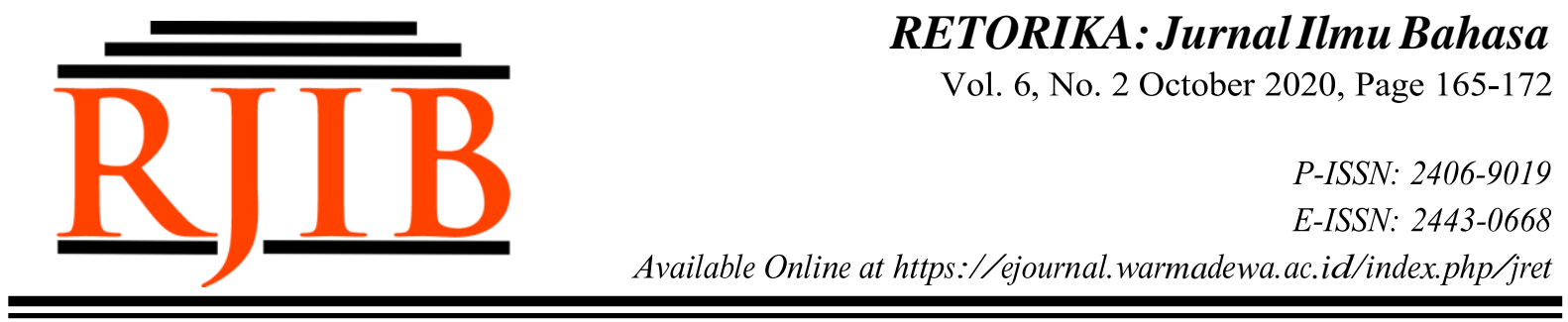

\title{
The Communicativeness and Critical Thinking Devices of Language Supplementary Materials for Primary School
}

\author{
Rohmani Nur Indah*, Galuh Nur Rohmah \\ Universitas Islam Negeri Maulana Malik Ibrahim Malang \\ *indah@bsi.uin-malang.ac.id
}

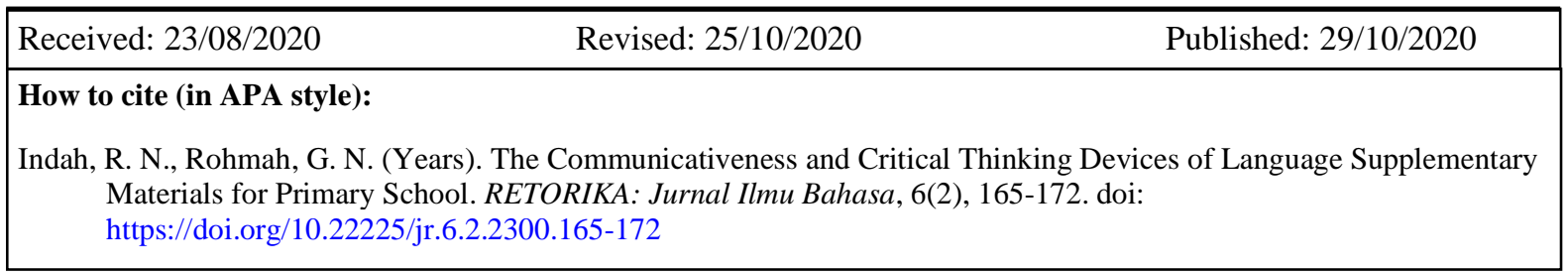

\begin{abstract}
Studies show that teaching materials can be integrated with critical thinking skills for enhancing successful learning. However, the integration is not always clear as the communicativeness aspect of the materials also contributes to the goal of effective learning. This study focuses on critical thinking devices and the aspect of communicativeness fulfilled or violated in Indonesian primary school supplementary materials for language courses. It employs content or document analysis on the supplementary materials of the first graders on courses of English, Indonesian and Javanese languages. The analysis is based on the assumption that critical thinking tools and communicative aspects are the two main pillars that characterize the quality of language teaching materials in elementary schools. In addition, critical thinking tools are linked with communicative aspects of language teaching materials to target targeted competency standards. The results show that the communicativeness aspect is supported by the use of real context and authenticity of the materials. In terms of critical thinking device, the supplementary materials are supported by clear purpose in presenting key information. The evaluation on the supplementary materials concerns with the effort to improve the quality of primary school student's cognitive attainment and critical thinking through communicative supplementary materials.
\end{abstract}

Keywords: Communicativeness; Content Evaluation; Critical Thinking; Supplementary Materials

\section{INTRODUCTION}

The 4.0 era emerges essential $4 \mathrm{C}$ skills; communication, collaboration, critical thinking and creativity, for students (Kemendikbud, 2017). It means that there is an urgent call to deeply study whether in the learning process students have been facilitated to hone these skills. As part of learning process, the teaching materials are potential space to accommodate the 4C skills. The teaching materials need to be examined whether it has supported the need for communicative teaching materials and is loaded with critical-sized devices.

The quality of teaching materials indeed has been a significant challenge in the implementation of K-13 today. This curriculum becomes a choice for thematic teaching with the benefit of giving more flexibility for teachers to adapt the materials to fulfill the student's need (Maryani \& Martaningsih, 2015). Meanwhile, the former curriculum, KTSP, gave the teachers opportunity to select and develop their own materials which are appropriate to their class and meet their student's need (Maghfiroh, 2011). 
Materials are the heart of learning that play important role to support the teaching and learning activities that can be regularly used by teachers as guidance (Sheldon, 1988). It should include certain components such as unified flow of information, absence of stereotypes, biases and development of insight as well as thinking skills. Therefore, teachers need to encourage the students to learn and attain the critical thinking through supplementary materials. However, there was a lack for textbook accommodating the students' different interests and needs (Cunningsworth, 1995).

As important supplementary materials, workbook offers flexibility to use (Nurcahyo \& Rachmajanti, 2013). To strengthen its usage, the content of the workbook should be intensively evaluated leading to the success of teaching and learning (Cunningsworth, 1995). In this regard, the materials should be assessed not only in one aspect such as suitability with the curriculum but also from several indicators. In this study, communicativeness and critical thinking devices become the focus as they are intertwined.

A communicative material tries to reflect the student's needs and interests. In addition, it emphasizes on fluency not just accuracy. Thus, it encourages the skills in using the language, not just in the forms of language so that it is activity based. It also tends to be very specific in the definition of aims by comprising both content and method that reflect the authentic language of everyday life. Another significant characteristic is supporting student's work in groups and pairs (Hadfield, 1989).

There are various criteria proposed by several experts in determining the quality of course book. Indonesia also has a national board namely the Board of National Education Standard. It guarantees the quality of the supplementary materials which will be used by teachers and students. In this study, the criteria for evaluating the content of the supplementary materials are adapted from some experts such as Cunningsworth (1995) and Harmer (2007).

In this study, the supplementary materials analyzed are those given in the K-13 (Kemendikbud, 2013). Until recently, teachers are challenged to meet the needs of their students so that they should be able to adapt with the primary school regulation concerning the curriculum chosen. This curriculum arranges the materials with thematic orders. Based on preliminary studies conducted in the primary school in Malang, the problems occur in the use of supplementary materials such as student work books. Not only teachers but also parents claim that the supplementary materials need more revision to facilitate student's reading comprehension. A careful evaluation from this study will lead to the quality of materials and will support students' critical thinking.

In language learning contexts, some studies relate the effectiveness of materials by relating to pedagogical value (Riasati \& Zare, 2010), to the fulfilment of learning objectives (Riaz \& Mosalanejad, 2010), or to the clarity and inclusiveness of the textbooks used. These studies concern with tertiary or secondary education. Meanwhile, evaluation on supplementary materials in first graders of primary level is urgent.

Primary school students are at the initial stage of literacy level. Their literal reading comprehension skill should be firstly built leading to their critical reading skill. They should have intensive exposure on reading material stimulating them for literal, inferential and critical reading. Literal reading leads to identifying written facts involving analyzing and reorganizing ideas. Inferential reading involves interpreting implied meaning, general inferring or interpreting the whole content. While, critical reading covers showing philosophical judgement and appreciation on the author's agreement or disagreement (Barret 1974 in Indah, 2012).

This study was empirical bases which can contribute to the further aspects relating to the establishment of critical thinking integrated in teaching and learning process. This research was conducted by basing on the assumption that critical thinking tools and communicative aspects are the two main pillars that characterize the quality of language teaching materials in elementary schools. In addition, critical thinking tools are linked with communicative aspects of language teaching materials to target targeted competency standards.

The result of this study also brings important institutional and pedagogical contributions. Institutionally, understanding the quality of the supplementary materials used in the primary school in Malang is an important step to map the quality of language teaching and learning. Specifically, it can be used to develop teaching syllabus, material and evaluation method focusing on student's critical thinking. As the pedagogical significance, assuring the 
quality of critical thinking devices in the supplementary materials is equal to the steppingstone to further develop student's academic achievement and later on the success of their future both academic and career.

Aspects of critical thinking should be involved in language learning. It becomes a means to apply higher-order thinking to enhance students' thinking skill in facing the situation related to classroom contexts (Richard, 2006). Critical thinking involves capacities ranging from identifying a problem to making inference. Judgment is based on the validity and reliability of the assumptions, sources of data or available information (Hofreiter, Monroe, \& Stein, 2007; Wade, 1995). These activities are not done all at once but they belong to stages of critical thinking done in continuum or in cyclic process. It results in the intellectual practices to constructs intellectual ends as clarity, precision, accuracy, relevance, depth, broadness, and rationale (Ernst \& Monroe, 2006).

Based on Paul \& Elder (2012), there are some critical thinking devices. The first is the ability to identify the author's purpose by being aware of the aim of the text. The second is the ability to raise key question by looking at the contextual reference. The third is the ability to grab important information in the supporting details. The fourth is the ability to infer by understanding the implied meaning of the text. The fifth is the ability to integrate the inference and comprehension questions. The sixth is the ability to make generalization from the information given in the text. And, the seventh is the ability to have similar perspective with the idea given in the text.

Effective reading materials cover: 1) language use which concerns with the appropriateness of grammar and vocabulary (Cunningsworth, 1995); 2) context referring to the real use of language which can also relate with the world beyond to promote holistic learning (Richard, 2006); 3) predictability concerns with the systematic organization of the text structure which is in the order from general to specific information; 4) information gap that is given though the communicative activities in the comprehension question for classroom meaningful activity (Harmer, 2007; Richard, 2006); 5) authenticity which is assessed though the quality of the text content using real fact and information instead of made-up content (Cunningsworth, 1995).
Studies on critical thinking is basically done by identifying the learners' need and interest to support their expertise (Indah, 2010) and supported by materials to foster learner's critical thinking (Indah, 2012). To assess this skill, reflective writing can be used to express learners' critical thinking bilingually. To have ideal critical thinking expression, the instruction should be well managed (Indah, 2013) through collaborative work. The focus on critical thinking on her dissertation is also linked with other variables (Indah, 2013).

Critical thinking based instruction becomes to key to produce critical thinkers as found in her research observing an Australian primary school. Identifying the factors affecting critical thinking is also a key for the readiness to organize critical thinking based instruction in university setting (Indah, 2017). It is expected that the critical thinking of students is well constructed without logical fallacies (Indah, 2014) or any relevant problems such as stabilized errors and promoted through several means inside and outside the classroom context (Indah, 2014).

The development of critical thinking should be guided as early as possible. Accordingly, this research focuses on the critical thinking device reflected in the supplementary materials used in primary school curricula namely K-13. As critical thinking also affected by communicativeness, the aspects supporting the quality of good materials are evaluated in this study. Therefore, the main goal of this study is to assess the communicativeness and critical thinking device in the supplementary materials. As the delimination of the analysis, there are two objectives formulated to do this research. First, this study is to assess the communicativeness of the supplementary materials used in K-13. It explores the aspects of communicativeness such as language use, real context, predictability, information gap, interactivity and authenticity. Second, the analysis done in this study aims at identifying the critical thinking devices which facilitate student's learning. The devices are traced from the fulfilment of the communicative aspects of the supplementary materials.

\section{METHODS}

The present study employs qualitative design aiming at answering the research problems which reflect the real situation at the time of the study. The researchers held the major 
role to gain sufficient data to understand the phenomenon better and to come at the deeper understanding on the communicativeness and critical thinking devices found. Content analysis method was used to identify the quality of the supplementary materials both in communicativeness and critical thinking devices.

The data needed for revealing the quality of communicativeness and critical thinking devices were in the form of reading comprehension task in the workbook as supplementary materials. As this study concerned with the context of language teaching and learning, the reading comprehension task analyzed were those in English, Bahasa Indonesia, and Javanese language. The source of the data was the workbook of primary schools used in Malang which widely use K-13.

To collect the data, there were instruments prepared in the form of checklist. There were two checklists used in this research. The first checklist was on the aspects of communicativeness adapted from Cunningsworth (1995) and Harmer (2007). It covers the criteria concerning language use, real context, predictability, information gap and authenticity. Each component has certain description points and each description point had range of score 0 , 1, 2. Score 0 meant that the content of the reading comprehension task did not fulfill certain description point. Score 1 means that the reading comprehension task partly fulfilled certain point. Lastly, score 2 means the reading comprehension task fulfilled certain description point well.

Then, the second checklist was adapted from Paul \& Elder (2012) concerning the criteria of critical thinking devices supported by the reading comprehension task. They are purpose, key question, important information, inferences, key concept, assumption, and point of view.
Each aspect has certain description points and each description point had range of score $0,1,2$. Score 0 meant that the content of the reading comprehension task did not fulfill certain description point. Score 1 means that the reading comprehension task partly fulfilled certain point. Lastly, score 2 means the reading comprehension task fulfilled certain description point well.

The data analysis began with describing the description point on each category, starting with the communicative aspects. Then it proceeded with analyzing the devices of critical thinking which fulfilled from the identification of the communicativeness. It completed the portrayal of the phenomenon regarding the quality of the primary school supplementary materials. The next process was comparing between the criteria in K-13 curriculum. The further step was to confirm the finding with the theoretical framework and previous studies concerning the quality of materials. Any similarities and differences gained from the finding and the empirical bases of this study were contributed to the final stage of the data analysis namely drawing conclusion.

\section{RESULT AND DISCUSSION}

There were seven data employing reading texts in Bahasa Indonesia, one datum in English and two data in Javanese language. In this section, the data analysis began with describing the description of each data followed by the finding on the category of communicativeness. Then it proceeded with analyzing the devices of critical thinking which fulfilled from the identification of the communicativeness.

\section{- The communicativeness of the supplementary materials}

Table 1

The communicativeness

\begin{tabular}{|c|c|c|c|c|c|c|}
\hline Topics & $\begin{array}{c}\text { Language } \\
\text { use }\end{array}$ & $\begin{array}{c}\text { Real } \\
\text { context }\end{array}$ & Predictability & Interactivity & Authenticity & Total \\
\hline 1. Reading habit & 1 & 1 & 0 & 1 & 2 & 5 \\
\hline 2. Poetry & 1 & 2 & 1 & 1 & 2 & 7 \\
\hline 3. Parental care & 1 & 2 & 2 & 1 & 1 & 7 \\
\hline 4. Community service & 1 & 2 & 1 & 1 & 2 & 7 \\
\hline 5. Caring sick people & 0 & 2 & 0 & 1 & 1 & 4 \\
\hline 6. Holiday & 1 & 2 & 0 & 1 & 2 & 6 \\
\hline 7. Market day & 0 & 1 & 1 & 2 & 1 & 5 \\
\hline 8. Study group & 1 & 2 & 1 & 1 & 2 & 7 \\
\hline 9. Daily activities & 1 & 2 & 0 & 1 & 1 & 5 \\
\hline 10. Trip & 1 & 2 & 2 & 1 & 2 & 8 \\
\hline
\end{tabular}


The average communicativeness score is 6 out of the possible highest score 10 . It means that this criterion is partly fulfilling the communicativeness aspect supported by good real context and authenticity, sufficient language use, predictability, and interactivity.

In the texts given, the context is related with the world beyond to promote holistic learning (Richard, 2006). Two data cover school context involving the reading activities in the classroom (data 1 and data 2). The rest data concern with the family life, activities at home and during holiday. The context is also supported by the use of image effective to help student's understanding (Derewianka \& Jones, 2016).

Authenticity is considered good as it shows the quality of the text content using real fact and information instead of made-up content (Cunningsworth, 1995). The efficacy of authentic materials is also supported by the finding in the context of teaching English as foreign language in Iran (Akbari \& Razavi, 2015; Gilakjani \& Sabouri, 2016). It ends at the improvement of student's skills in vocabulary, comprehension, spelling and fluency (Hudson \& Williams, 2015).

The language learning either in English, Indonesian or Javanese language is given through the reading comprehension text. It is expected that the learners acquire not only appropriate use of grammar but also vocabulary (Cunningsworth, 1995). In this case, appropriate punctuation such as the use of capitalization and period becomes the dominant error as found in Indonesian language (data 1 , data 2 , data 5 , and data 6), In Javanese language (data 10). Spelling error occurs in Indonesian language (data 3 and data 4). Missing transition is identified in Indonesian language (data 1). Error in vocabulary is found in Indonesian language (data 4 and data 7$)$.

In the analyzed supplementary materials, the aspect of predictability is supposed to concern with the systematic organization of the text structure which is in the order from general to specific information. The material should present consistent structure so that learner can predict the sequence of ideas given in the text (Richard, 2006). The predictability is influenced by the correct order and the relevance from general to specific information which is missing in the text in Indonesian language (data 1, data 5, and data 6) and in Javanese language (data 9). However, the absence of predictability means that language can be understood and learned without the ability of making prediction. This finding is in line with the view of Huettig \& Mani (2016).

Interactivity also becomes a significant criterion as it provides information gap and supports the meaningful activity for classroom context (Richard, 2006). The interactivity is built through post reading activities which are mostly in the form of group or pair works to discuss an exercise (data 2, 4, 7, 8, 9, and 10) that can be an interview report or telling stories using given illustration. The task can also involve parents (data 1 and data 6) or singing activity (data 3 and data 5). That interactivity in reading task is a significant element supported by explicit instruction.

\section{- The critical thinking device of the supplementary materials}

Table 2

The critical thinking devices

\begin{tabular}{|c|c|c|c|c|c|c|}
\hline Topics & $\begin{array}{c}\text { Purpose/key } \\
\text { question }\end{array}$ & $\begin{array}{l}\text { Important } \\
\text { information }\end{array}$ & $\begin{array}{l}\text { Inferences/key } \\
\text { concept }\end{array}$ & Assumption & $\begin{array}{c}\text { Point of } \\
\text { view }\end{array}$ & Total \\
\hline 1. Reading habit & 2 & 1 & 0 & 1 & 1 & 5 \\
\hline 2. Poetry & 2 & 1 & 0 & 1 & 1 & 5 \\
\hline 3. Parental care & 2 & 1 & 0 & 0 & 1 & 4 \\
\hline 4. Community service & 2 & 1 & 0 & 0 & 1 & 4 \\
\hline 5. Caring sick people & 2 & 1 & 0 & 0 & 1 & 4 \\
\hline 6. Holiday & 2 & 1 & 0 & 0 & 1 & 4 \\
\hline 7. Market day & 2 & 1 & 0 & 0 & 1 & 4 \\
\hline 8. Study group & 2 & 2 & 0 & 1 & 1 & 6 \\
\hline 9. Daily activities & 2 & 1 & 0 & 0 & 0 & 3 \\
\hline 10. Trip & 2 & 2 & 0 & 1 & 1 & 6 \\
\hline
\end{tabular}


The average critical thinking device score is 5 out of the possible highest score 10. It means that this criterion is partly fulfilling the aspect of critical thinking device supported by good purpose and key question, sufficient information, sufficient point of view, poor inferences and key concept, and poor assumption.

There are some critical thinking devices reflected. The most identifiable one is the purpose related to the ability to identify the author's purpose by being aware of the aim of the text. It is shown by the clear statement in the text concerning the general information (Paul \& Elder, 2012). The students can understand the purpose of each reading text as the instruction in all data is clear.

In the finding, it appears that important information in the form of facts, experience or any supporting details are given through the text. The information is also presented explicitly in the text and given in the comprehension question. It falls in the category of sufficient or partly fulfilling the expected criteria as not all reading text is followed by comprehension questions. It is in line with the view of Wasik, Hindman, \& Snell (2016) that explicitly defining words in the textbook designed for children belongs to an effective strategy to improve learner's comprehension.

The point of view aspect falls into the category of sufficient as the reader or the learner can have similar perspective with the idea given in the text. Some post reading tasks has elaborated the context similar to that available in text content. It is also given by the comprehension questions following the reading text.

In most of the reading text analyzed, inferences to support reader's understanding on the implied meaning of the text are not given. In this case, the comprehension questions elicit the learner's understanding on the explicit information in the text. The exercise on implied meaning is not given considering that the supplementary materials are given to the first year students of primary school. Therefore, the concept that is inferred from the text also is not available. Inferencing demands higher order critical thinking supported by advanced level of reading strategy (Thamrin \& Agustin, 2019).

The fact that inferencing skill does not become an emphasis in the primary school supplementary materials in the course of English, Bahasa Indonesia and Javanese language is far different from another finding. Silva \& Cain (2015) found that inferencing skill becomes critical in construction of text representation particularly for young learners.

Similarly, the aspect of assumption that gears the ability to make generalization from the information given in the text does not belong to the focus of the post reading activities. The learners' understanding through the comprehension questions are given to enable the student's ability on making concrete conclusion not other assumption. Borrowing the term of memory representation, when students tried to understand the information in the text by relating to their explicit memory representation, it results in better comprehension (Hill, Bordes, Chopra, \& Weston, 2015).

Regarding the course content as identified in the national standard of competence based on 2013 curriculum, the communicativeness and critical thinking device of the supplementary materials are sufficient and relevant to achieve the standard. The descriptive texts analyzed have given the criteria as stated in Curriculum 2013 standard competence as follow: First, enabling students to recognize descriptive text on body, part of the body, senses (data 2), form and structure of things (data 1), the activities during days (data 4, 6, 7, 9, and 10) or nights. Second, it enables students to understand instruction on how to care on bodies, maintain health (data 4 and 5). Third, the materials enable students to recognize the context of appreciating (data 2) and caring others (data 3, 5, 6, 7, and 10). Fourth, the supplementary materials support students to explore about oneself (data 8 and 9) and family (data 3, 5, 6, 7, and 10). Finally, it also supports the students to label and understand family tree (data $3,5,6,7$, and 10).

\section{IV.CONCLUSION}

This study has assessed the communicativeness of the supplementary materials used in primary school using 2013 curriculum. It explored the aspects of communicativeness such as language use, real context, predictability, information gap, interactivity and authenticity. The finding showed that communicativeness of the supplementary materials was partly fulfilling the communicativeness criteria supported by good real context, good authenticity, sufficient language use, sufficient predictability, and sufficient interactivity. 
The analysis done in this study also identified the critical thinking devices which facilitate student's learning. The devices are traced from the fulfilment of the communicative aspects of the supplementary materials. The data show that the critical thinking device score is also sufficient. It means that this criterion is to some extent supported by good purpose and key question, sufficient information, sufficient point of view, poor inferences and key concept, and poor assumption. However, the topics covered in the texts analyzed have fulfilled the national standard of competence based on 2013 curriculum through the communicativeness and critical thinking device employed.

Based on the conclusion explained above, some suggestion can be constructed. The identification of the quality communicativeness of the primary school supplementary materials has shown sufficient quality which is still not enough. Similarly, the standard of critical thinking device is also not satisfactory; therefore improvement and revision are severely needed. Thus, the education board or Dinas Pendidikan Malang should use the result of this study as a strong reason to strengthen the monitor and production process of the supplementary materials.

The results of this study also bring important institutional and pedagogical contributions. Institutionally, understanding the quality of the supplementary materials used in the primary school in Malang is an important step to map the quality of language teaching and learning in Malang. Further, it can be used to develop teaching syllabus, material and evaluation method which emphasizes on guiding student's critical thinking. In this case, it is expected that teachers make good selection of the supplementary materials. This is because this study shows that some texts have weaknesses and need revision.

\section{REFERENCES}

Akbari, O., \& Razavi, A. (2015). Using authentic materials in the foreign language classrooms: Teachers' perspectives in EFL classes. International Journal of Research Studies in Education, 4(5).

Cunningsworth, A. (1995). Choosing Your Coursebook.

Derewianka, B. M., \& Jones, P. T. (2016). Teaching Language in Context.

Ernst, J. (Athman), \& Monroe, M. (2006). The Effects of Environment-Based Education on Students'
Critical Thinking Skills and Disposition toward Critical Thinking. Environmental Education Research, 12(3-4), 429-443.

Gilakjani, A. P., \& Sabouri, N. B. (2016). A Study of Factors Affecting EFL Learners' Reading Comprehension Skill and the Strategies for Improvement. International Journal of English Linguistics, 6(5), 180.

Hadfield, J. (1989). Reviews: Making the Most of Your Textbook (Neville Grant Longman 1987). ELT Journal, 43(2), 158-159.

Harmer, J. (2007). How to Teach English.

Hill, F., Bordes, A., Chopra, S., \& Weston, J. (2015). The Goldilocks Principle: Reading Children's Books with Explicit Memory Representations.

Hofreiter, T. D., Monroe, M. C., \& Stein, T. V. (2007). Teaching and Evaluating Critical Thinking in an Environmental Context. Applied Environmental Education \& Communication, 6(2), 149-157.

Hudson, A. K., \& Williams, J. A. (2015). Reading Every Single Day: A Journey to Authentic Reading. The Reading Teacher, 68(7), 530-538.

Huettig, F., \& Mani, N. (2016). Is Prediction Necessary to Understand Language? Probably not. Language, Cognition and Neuroscience, 31(1), 19-31.

Indah, R. N. (2010). Discovering Student's Expertise to Augment Claim Quality in Writing Class at UIN Maliki Malang.

Indah, R. N. (2012). Communicating Critical Thinking through Bilingual Reflective Writing.

Indah, R. N. (2013). Reformulating Reading Materials to Foster Student's Critical Thinking.

Indah, R. N. (2014). Stabilized Errors: Attributed Problem in Timed and Non-Timed Argumentative Writing. LiNGUA: Jurnal Ilmu Bahasa Dan Sastra, 9(2).

Indah, R. N. (2017). Critical Thinking, Writing Performance and Topic Familiarity of Indonesian EFL Learners. Journal of Language Teaching and Research, 8(2), 229.

Kemendikbud. (2013). Kompetensi Dasar SD/MI.

Kemendikbud. (2017). Panduan Penilaian oleh Pendidik dan Satuan Pendidikan untuk Sekolah Menengah Atas.

Maghfiroh, M. L. (2011). The quality of student book "Bahasa Inggris for Junior High School Year VIII (Universitas Negeri Malang).

Maryani, I., \& Martaningsih, S. T. (2015). Correlation between Teacher's PCK (Pedagogical Content Knowledge) and Student's Motivation in Primary School in Indonesia. International Journal of Evaluation and Research in Education (IJERE), 4(1), 38.

Nurcahyo, T. W., \& Rachmajanti, S. (2013). A Review on English Workbook "Excellent" Used by 12th Graders at SMAN 1 Lawang (Universitas Negeri Malang).

Paul, R., \& Elder, L. (2012). The International 
Critical Thinking Reading and Writing Test.

Riasati, M. J., \& Zare, P. (2010). Textbook Evaluation: EFL Teachers' Perspectives on "New Interchange." Studies in Literature and Language, 1(8).

Riaz, A. M., \& Mosalanejad, N. (2010). Evaluation of Learning Objectives in Iranian High-School and Pre-University English Textbooks Using Bloom's Taxonomy. TESL-EJ, 13(4).

Richard, J. C. (2006). Communicative Language Teaching Today.

Sheldon, L. E. (1988). Evaluating ELT Textbooks and Materials. ELT Journal, 42(4), 237-246.

Silva, M., \& Cain, K. (2015). The Relations between Lower and Higher Level Comprehension Skills and Their Role in Prediction of Early Reading Comprehension. Journal of Educational Psychology, 107(2), 321-331.

Thamrin, N. R., \& Agustin, S. (2019). Conceptual Variations on Reading Comprehension through Higher Order Thinking Skills (HOTS) Strategy. English Review: Journal of English Education, 7(2), 93.

Wade, C. (1995). Using Writing to Develop and Assess Critical Thinking. Teaching of Psychology, 22(1), 24-28.

Wasik, B. A., Hindman, A. H., \& Snell, E. K. (2016). Book Reading and Vocabulary Development: A Systematic Review. Early Childhood Research Quarterly, 37, 39-57. 